\title{
Modelos familiares y vejez en España. Siglos XVIII a XX
}

\author{
Fernando Mikelarena* \\ Pilar Pérez-Fuentes**
}

En primer lugar, el articulo pretende comprobar si existia alguna relación entre la pluralidad de los modelos familiares en España y una mayor o menor longevidad. Relacionando entre si indicadores de complejidad de hogares y de longevidad de la población, elaborados a partir del censo de 1860, comprobamos que la diversidad de modelos familiares no pueden constituir un factor explicativo de la longevidad.

En segundo lugar abordamos un mosaico de situaciones históricas en las que analizamos cómo se afrontaba la vejez en España en relación con los diferentes modelos familiares. En las zonas murales se afrontaba la vejez de manera muy diferente según el modelo familiar predominante. Asi en la provincia de Cuenca a lo largo de los siglos XVIII a XIX la vejez significaba soledad mientras que en Navarra en el XVII, los ancianos vivian preferentemente en hogares complejos.

Los espacios urbanos nos presentan una variedad de situaciones en las que el modelo familiar dominante pierde capacidad explicativa para dar paso a otros factores como las inmigraciones, las dinámicas de los mercados de trabajo, las pautas de nupcialidad y especialmente los niveles de celibato définitivo y los roles de género. En el siglo XVII, en Pamplona, ciudad donde predominaba el modelo de familia troncal, los ancianos vivian en hogares complejos, aunque en menor proporción que en las zonas rurales colindantes. El caso de Bilbao, centro económico del norte de España y con notable predominio de los hogares simples, nos muestra cómo la solidaridad con los mayores también puede ser compatible con este modelo familiar. La imagen de que en las ciudades industriales los ancianos vivian en hogares solitarios, contrasta con el elevado número de mayores que vivian en hogares complejos o incluso nucleares. Por último, San Salvador del Valle nos muestra los efectos que tuvo sobre la vejez la industrialización zcelerada acompañada de fuertes inmigraciones masculinas, pero también, la posterior apacidad de adaptación de la familia nuclear para integrar a los mayores en hogares omplejos.

Pese a los diferentes modelos familiares que existian en España a lo largo de los silos XVIII a XX podemos concluir que éstos no afectaban a la longevidad de las personas i a las pautas de solidaridad con los mayores y que por el contrario, la solidaridad onstituye uno de los rasgos de la cultura familiaria lo largo de toda su geografía.

\section{atroducción}

pesar del impulso que la historia de la familia ha tenido en los últiios años en España, existe, sin embargo, un gran vacío en lo que se fiere a la producción histórica acerca de lo que ocurre con el enve-

\footnotetext{
* Universidad de Zaragoza.

** Universidad del País Vasco.
} 
:jecimiento y las formas de vida de nuestros mayores en el pasado. El objetivo de este artículo es aportar algunos datos y reflexiones sobre la situación de los ancianos en diferentes contextos de España en los siglos XVIII a XX, centrándose en las relaciones entre los modelos familiares y la vejez. El artículo se estructura en cuatro apartados. En el primero analizaremos los modelos familiares existentes en España a partir de una cartografia realizada para todo el país fundamentada en indicadores que se basan en cifras del censo de 1860. En el segundo apartado estudiaremos el grado de asociación entre los modelos familiares y la longevidad en el conjunto de España. En tercer lugar, examinaremos cómo afrontaban los ancianos la vejez en cinco contextos concretos: dos rurales -uno de familia nuclear y otro de familia troncal-; dos urbanos -uno tradicional y otro moderno-; y el último minero-industrial. En cuarto y último lugar, repasaremos cuáles eran las pautas de asistencia a la vejez en España, centrando nuestra mirada en los ámbitos rurales tradicionales debido a que hasta el momento esas pautas han sido descritas solamente para esas zonas.

Pretendemos con este artículo reflejar el estado actual de las investigaciones sobre la vejez en España y colaborar con resultados, reflexiones e hipótesis a un mayor impulso de estos temas en el campo de la demografía histórica.

\section{Los modelos familiares en España}

La cuestión de la concreción del número y caracteres de los modelos familiares existentes en España es ya una cuestión resuelta gracias a las aportaciones de diversos investigadores, cuyas reflexiones globales se han referido a la totalidad del territorio español.

La primera aportación data de los años setenta y su autor fue el antropólogo Lisón Tolosana (1975). Para él, los modelos familiares existentes en España eran solamente dos: el modelo familiar nuclear (relacionado con una regla de establecimiento neolocal de los matrimonios y con un régimen de herencia igualitario de división a partes iguales entre los hijos) y el modelo troncal (asociado a una regla de establecimiento patrilocal y a un régimen de herencia indiviso de transmisión íntegra del patrimonio a un único heredero). Fundamentándose tal autor en la literatura etnológica disponible, considera que la geografia de tales modelos familiares es la siguiente: la familia nuclear se localizaría espacialmente en las ciudades, la parte central de Oren- 
se, las dos Castillas, la provincia de Zaragoza y la mayor parte de Teruel en Aragón, el centro y sur de Navarra, el sur de Cataluña, Valencia, la mayor parte de Castellón, Murcia, Extremadura y Andalucía. La familia troncal se expandería por algunas zonas de Galicia (como el noreste de La Coruña, el noroeste de Pontevedra, el este de Lugo), zonas de la montaña asturiana y cántabra, el País Vasco, el norte de Navarra, el Alto Aragón, la mayor parte de Cataluña y las Islas Baleares. Asimismo, existirían enclaves de familia troncal en comarcas castolenses, valencianas y turolenses.

Posteriormente otro antropólogo, Contreras (1991), matizó la visión dualista de Lisón que contraponía la familia nuclear con la familia troncal, y llamó la atención sobre la existencia del sistema hereditario preferencial, además del indiviso y del igualitario, y sobre la presencia de una gama mayor de tipos de familia relacionada con ese abanico más amplio de regímenes de herencia. Asimismo, Contreras insistía en que, de ser tenidas en cuenta algunas costumbres relativas al ciclo de vida de las familias (como la corresidencia de jóvenes esposos junto con sus padres en la misma casa durante uno o varios años, o como la corresidencia en rotación de los padres ancianos en la casa de alguno de sus hijos durante algunos meses) en zonas aparentemente de familia nuclear, todavía habría una pluralidad mayor de modelos familiares. Hay que precisar que, según él, dichas costumbres incidirían sobre todo en zonas de Castilla, Andalucía y la Rioja.

Esas consideraciones fueron corroboradas por uno de los autores de este artículo en un texto (Mikelarena, 1992) donde trazaba una cartografía familiar fundamentada en el cálculo de diversos indicadores estimados a partir de una serie de datos presentes para los distintos partidos judiciales españoles en el censo de 1860. Esos indicadores eran el número de personas casadas y viudas por hogar, el número de mujeres casadas y viudas por hogar; y el número de personas adultas por hogar. En aquel texto se indicaba la existencia de zonas en las que predominaría socialmente la familia troncal patrilocal, de zonas donde la familia nuclear sería la mayoritaria, por último, y de zonas en las que se advertía la presencia de situaciones familiares intermedias en la medida en que en ellas los valores correspondientes a los indicadores empleados en relación con las estructuras familiares se encontraban entre los denotadores del predominio social de la familia troncal y los denotadores del predominio de la familia nuclear. En principio, esas situaciones familiares intermedias podrían ser resultantes de causas como las apuntadas por Contreras; es decir, del hecho en última instancia de 
que en España pueden diferenciarse diversos grados de nuclearidad, constatándose una familia nuclear propiamente dicha y una familia nuclear con una cierta incidencia de estructuras complejas en ciertos momentos del ciclo vital familiar. Ahora bien, el mismo autor también puso de relieve que, aparte del modelo familiar predominante existente en un espacio geográfico, también podían haber modelos minoritarios seguidos por sectores sociales determinados en función de sus intereses. Guiándose de ejemplos locales, mostró que eso era palpable tanto en las zonas en las que preponderaba la familia troncal (en las que las familias de arrendatarios y de jornaleros podían seguir pautas de familia simple) como en las que dominaba la familia nuclear (en las que los hogares de los sectores sociales con más recursos tendían a presentar estructuras complejas).

La geografía de esos modelos familiares existentes en España puede apreciarse según la distribución espacial por el territorio español de las cifras por partidos judiciales de mujeres casadas y viudas por hogar. Las zonas con más de 1075 mujeres casadas y viudas por hogar serían las propias de la familia troncal. Las zonas con menos de 1000 mujeres casadas y viudas por hogar serían las que tendrían a la familia nuclear como modelo mayoritario. Las pautas intermedias estarían vigentes en las zonas en las que el indicador se ubica entre esos dos extremos. Pues bien, bajo todo ello indica que la familia troncal como modelo familiar socialmente predominante se localiza en casi toda Cataluña, la provincia de Huesca en su integridad, los dos partidos judiciales del norte de Zaragoza, los partidos navarros de Pamplona, Aoiz y Estella, toda Guipúzcoa, el norte de Alava, la mayor parte de Vizcaya y algunos partidos judiciales dispersos de Cantabria, Asturias, Lugo, Teruel, Valencia y Baleares. Por su parte, todo el resto de España se caracterizaría por el modelo familiar nuclear, a excepción de algunas zonas de la costa levantina, desde Sevilla hasta Castellón, y de otras de la cornisa cantábrica caracterizadas todas ellas por el modelo familiar intermedio.

Como es obvio, la situación de los viejos en esos modelos estaba estrechamente vinculada al ciclo de vida familiar propio de tales modelos. En principio, el ciclo de vida de una familia de pautas rigurosamente nucleares podría atravesar por la siguiente serie de etapas: una primera etapa de constitución de una nueva unidad familiar en la que solamente están presentes los dos cónyuges; una segunda etapa en la que los hijos que progresivamente van naciendo se van incorporando al hogar; una tercera etapa en la que los hijos progresivamente 
van saliendo del hogar conforme se van casando y van constituyendo grupos domésticos autónomos; una cuarta etapa en la que, tras el matrimonio de todos los hijos, los padres vuelven a estar solos; y una quinta y última etapa en la que, tras la muerte de uno de ellos, la unidad familiar está constituida por una persona viuda hasta el momento en que ésta fallezca y la unidad familiar desaparezca con ella.

Obviamente, esa secuencia se vería alterada si la muerte de uno o de los dos cónyuges se produjera con anterioridad al momento en que la totalidad de los hijos hubiese abandonado la casa paterna. Con todo, es lícito afirmar que la morfología concreta que puede adoptar una familia nuclear en un momento determinado se traduce en las siguientes tres categorías de la tipología clasificatoria laslettiana: 1) hogares nucleares o simples en los que un núcleo conyugal se presenta con hijos o sin hijos; 2) hogares solitarios donde una persona viuda, abandonada por sus hijos, constituye la unidad familiar, y 3) hogares sin estructura, en el caso de que, muertos los padres, el hogar esté constituido únicamente por sus hijos solteros.

A su vez, la familia troncal se basa en la presencia de una línea genealógica que se corresponde habitualmente con la presencia de dos núcleos conyugales ligados entre sí por vínculos paterno-filiales. Asimismo, en la composición de estos grupos domésticos quedarán incluidos junto a los miembros de los núcleos conyugales de la línea troncal y los descendientes del núcleo conyugal másjoven, los parientes colaterales solteros que no hayan alcanzado la edad de tomar estado matrimonial o que hayan decidido permanecer célibes en la casa tamiliar. Los parientes solteros pueden abandonar el hogar paterno, recibiendo una compensación en metálico o en especie que les ayude a contraer matrimonio con el heredero o heredera de otro patrimonio en la unidad familiar de este último, o les permita contraer matrimonio neolocal con otra persona no heredera de ningún otro patrimonio, o les ayude a montar negocios o ejercer profesiones fuera del entorno familiar y en estado civil de soltería. Los parientes solteros que no deseen abandonar la casa paterna pueden permanecer en ella yozando del cuidado y la manutención del titular del patrimonio y rabajando en beneficio de la hacienda familiar. Así pues, en los monentos de máxima amplitud de este tipo de familia podrían convivir lasta tres generaciones dentro de un mismo grupo doméstico: la de os padres y tíos y tías solteros del núcleo conyugal del que forma pare el hijo o hija de la casa instituido como heredero; la del núcleo :onyugal heredero y de sus hermanos y hermanas solteros; y, por últi- 
mo, la de los hijos e hijas de ese núcleo conyugal heredero. A causa de todo ello, el ciclo de vida de una familia de parámetros troncales presenta una amplia gama de etapas. En principio, cabe pensar que en el ciclo de vida de la familia troncal han de constatarse forzosamente tres etapas: una etapa primera en la que el núcleo conyugal del hijo o hija designado como heredero se establece junto a uno o los dos padres de ese hijo o hija; una segunda en la que han fallecido los padres y el núcleo conyugal de aquel hijo o hija instituido como heredero convive con sus hijos; y una tercera etapa en la que se vuelve a la situación inicial en el momento en queijunto al núcleo conyugal entonces instituido como heredero se instala el hijo o hija y su cónyuge, elegidos ahora como nuevos sucesores.

Ahora bien, además de esas tres etapas ineludibles, la familia troncal podía dar lugar a una variación mucho mayor de situaciones debido a las posibilidades que suponía el derecho que este sistema sucesorio y familiar proporcionaba a los hijos e hijas de la casa que no eran designados como herederos de continuar viviendo en ella en unión del núcleo conyugal constituido como sucesor, siempre y cuando permanecieran en estado civil de soltería.

Así pues, el ciclo de vida de la familia troncal podía dar lugar a las siguientes morfologías de los hogares, según el sistema de clasificación de los grupos domésticos que hemos propuesto, en los momentos puntuales a los que se refieren las listas nominales de habitantes: hogares simples (en el caso de que la familia troncal atravesara la etapa de su ciclo de vida en la que los miembros de la unidad conyugal designada como heredera vivieran únicamente con sus hijos, fallecidos sus padres y sin que, por circunstancias diversas, no cohabitara ijunto a ellos ningún pariente soltero) $\mathrm{u}$ hogares complejos (en el caso de que la familia atravesara la etapa de su ciclo vital en la que los miembros de la unidad conyugal heredera vivieran con o sin sus hiijos, corresidiendo con ellos los dos o alguno de los padres del heredero del patrimonio o también uno o varios parientes solteros de su misma generación o de la generación anterior).

El modelo familiar intermedio es una variación del modelo nuclear, haciendo que los hogares solitarios en los que residían los padres viudos desaparezcan en todo o en parte y aumenten los hogares extensos donde tal padre conviva con uno de sus hijos o hijas y con su cónyuge y quizás también con sus nietos.

Así pues, cada uno de estos modelos plantea una situación diferente para los ancianos. Si en el modelo familiar nuclear los viejos de- 
ben afrontar su situación en soledad, en el modelo familiar troncal estaban acompañados de sus familiares, permaneciendo siempre en el seno del mismo grupo doméstico. A su vez, en el modelo intermedio, al final de su vida padres o madres en estado de viudez podían residir de forma rotativa en casa de sus diversos hijos, pasando uno o varios meses con cada uno.

\section{Los modelos familiares y la longevidad}

Una forma indirecta de responder a la pregunta de cómo era la posición de los ancianos en los distintos modelos familiares es la de estudiar el grado de asociación entre modelos familiares y longevidad. Fauve-Chamoux (1985), al relacionar el peso de la población con edades superiores a 60 años con la complejidad familiar y las costumbres de la jefatura de la casa de una zona como la de las Baronías de los Pirineos centrales franceses donde la familia troncal tenía amplia presencia (aunque menor que la vista para el norte y centro de Navarra), concluyó que en el seno de tal modelo familiar "el anciano goza de una situación privilegiada". En España los análisis estadísticos también apuntan hacia el hecho de que la pauta troncal de estructuración familiar podría tener consecuencias favorables de cara a la consecución de una mayor longevidad. En Navarra, Mikelarena (1995: 304-305) ha calculado un coeficiente de correlación de 0.876 entre un indicador relativo al seguimiento de la pauta de troncalidad y la proporción de población de más de 50 años en las distintas comarcas en 1786.

Teniendo en cuenta que en el hecho de la longevidad también participan otros factores, intentaremos verificar si pueden apreciarse diferencias de alcance en lo relativo a la longevidad de la población en los diversos sistemas familiares en España. Nuestro intento se funtamenta en las cifras provinciales de individuos casados y viudos por logar (Indcv) y de mujeres casadas y viudas por hogar (Mujcv) y en as proporciones de población de más de 60 años (Pob60) y de más de 70 años (Pob70) de cada provincia en 1860. Todos esos datos se ecogen en el cuadro 1.

Tal y como se observa en el cuadro 2, donde se presentan los coeicientes de correlación deducidos de los valores de los indicadores lel cuadro 1, no puede afirmarse que exista asociación entre los molelos familiares y una mayor o menor longevidad. Relacionándose 
CUADRO 1

Complejidad familiar y longevidad en las provincias españolas en 1860

\begin{tabular}{|c|c|c|c|c|}
\hline & Pob60 & Pob70 & Indcv & Mujcv \\
\hline Alava & 6.83 & 1.91 & 2.085 & 1,068 \\
\hline Albacete & 5.91 & 1.64 & 1.892 & 0.986 \\
\hline Alicante & 5.45 & 1.58 & 1.918 & 1.021 \\
\hline Almería & 4.40 & 1.18 & 1.825 & 0.998 \\
\hline Ávila & 5.02 & 1.18 & 1.793 & 0.935 \\
\hline Badajoz & 4.63 & 1.18 & 1.884 & 0.962 \\
\hline Baleares & 8.20 & 2.77 & 1.870 & 1.012 \\
\hline Barcelona & 5.71 & 1.67 & 2.110 & 1.121 \\
\hline Burgos & 6.21 & 1.69 & 1.921 & 0.991 \\
\hline Cáceres & 4.62 & 1.06 & 1.784 & 0.909 \\
\hline Cádiz & 5.19 & 1.51 & 1.795 & 0.916 \\
\hline Canarias & 6.61 & 2.22 & 1.615 & 0.890 \\
\hline Castellón & 4.85 & 1.15 & 1.938 & 1.011 \\
\hline Ciudad Real & 5.69 & 1.53 & 1.873 & 0.970 \\
\hline Córdoba & 5.82 & 1.47 & 1.826 & 0.944 \\
\hline La Coruña & 6.17 & 1.44 & 1.778 & 0.976 \\
\hline Cuenca & 6.73 & 1.75 & 1.844 & 0.951 \\
\hline Gerona & 6.66 & 2.00 & 2.153 & 1.137 \\
\hline Granada & 5.14 & 1.28 & 1.904 & 1.005 \\
\hline Guadalajara & 6.05 & 1.48 & 1.869 & 0.961 \\
\hline Guipúzcoa & 7.47 & 2.79 & 2.177 & 1.136 \\
\hline Huelva & 4.85 & 1.22 & 1.773 & 0.924 \\
\hline Huesca & 5.62 & 1.33 & 2.308 & 1.188 \\
\hline Jaén & 4.97 & 1.22 & 1.919 & 0.985 \\
\hline León & 4.93 & 1.12 & 1.749 & 0.928 \\
\hline Lérida & 5.73 & 1.51 & 2.179 & 1.136 \\
\hline Logroño & 5.65 & 1.33 & 1.854 & 0.997 \\
\hline Lugo & 6.16 & 1.54 & 1.790 & 0.946 \\
\hline Madrid & 4.84 & 1.29 & 1.881 & 0.981 \\
\hline Málaga & 5.10 & 1.38 & 1.828 & 0.975 \\
\hline Murcia & 5.13 & 1.56 & 1.894 & 1.000 \\
\hline Navarra & 5.83 & 1.65 & 2.061 & 1.078 \\
\hline Orense & 5.56 & 1.23 & 1.640 & 0.867 \\
\hline Oviedo & 6.95 & 1.82 & 1.869 & 1.009 \\
\hline Palencia & 5.50 & 1.46 & 1.892 & 0.964 \\
\hline Pontevedra & 7.75 & 1.89 & 1.605 & 0.897 \\
\hline Salamanca & 5.35 & 1.32 & 1.763 & 0.915 \\
\hline Santander & 6.46 & 1.94 & 1.943 & 1.040 \\
\hline Segovia & 5.31 & 1.25 & 1.894 & 0.979 \\
\hline Sevilla & 5.60 & 1.50 & 1.832 & 0.942 \\
\hline Soria & 5.42 & 1.32 & 1.852 & 0.976 \\
\hline Tarragona & 5.87 & 1.66 & 2.098 & 1.108 \\
\hline Teruel & 5.76 & 1.32 & 1.954 & 1.026 \\
\hline Toledo & 6.41 & 1.61 & 1.843 & 0.944 \\
\hline Valencia & 5.20 & 1.37 & 1.959 & 1.030 \\
\hline Valladolid & 5.45 & 1.35 & 1.908 & 0.976 \\
\hline Vizcaya & 6.77 & 2.21 & 1.989 & 1.063 \\
\hline Zamora & 5.37 & 1.25 & 1.838 & 0.955 \\
\hline Zaragoza & 5.61 & 1.32 & 1.965 & 1.015 \\
\hline
\end{tabular}

Fuente: Censo de 1860. Datos elaborados por los autores. Para más detalles, véase el texto. 
entre sí los indicadores relativos a la complejidad familiar por un lado, y los indicadores relativos a la longevidad poblacional por otro, los coeficientes de correlación que se calculan a partir de relacionar los primeros con los segundos son muy bajos y, a excepción del que resulta de vincular la proporción de población mayor de 70 años con el número de mujeres casadas y viudas por hogar (que es de 0.342 ), carentes de significación alguna. Así pues, no parece que la diversidad de modelos familiares españoles tuviera repercusión sobre la longevidad. Posiblemente la razón de ello estribe en el hecho de que, contrariamente a lo que podría pensarse en un principio, y tal como se verá en el último apartado, la solidaridad con los ancianos incluso en el modelo nuclear, aparentemente más insolidario con ellos que el troncal, determinaba que en el tramo final de su vida contaran con la compañía y el apoyo de sus hijos.

CUADRO 2

Coeficientes de correlación obtenidos a partir de los valores de los indicadores del cuadro 1

\begin{tabular}{lllll}
\hline & Incv & Mucv & Pob60 & Pob70 \\
\hline Incv & \multirow{2}{*}{1.000} & $0.959^{* *}$ & 0.112 & 0.232 \\
Mucv & & 1.000 & 0.223 & $0.342^{*}$ \\
Pob60 & & & 1.000 & $0.880^{* *}$ \\
Pob70 & & & & 1.000 \\
\hline
\end{tabular}

* Significativo al nivel de 0.05 .

** Significativo al nivel de 0.01 .

Fuente: Valores del cuadro 1.

\section{Modelos familiares y vejez en diferentes contextos históricos}

En este punto examinaremos cómo afrontaban los ancianos la vejez en cinco contextos concretos. El primero es el de Cuenca, un contexto rural y agrario de familia nuclear, ubicándose los datos en los siglos XVIII y XIX. El segundo contexto corresponde a diversas comarcas del norte y centro de Navarra en 1786 , zonas rurales y agrarias en las que predominaba el sistema familiar troncal. El tercer contexto es urbano: Pamplona, la capital de Navarra, en 1786 , una ciudad de caracteres ciertamente tradicionales. El cuarto contexto es el de otra ciudad: 
Bilbao, la capital de Vizcaya, en 1825, 1900 y 1930, caracterizada por ser el foco de una zona de grandes cambios socioeconómicos. El quinto y último contexto se ubica en cuenca minera vizcaína, una zona cuyo rasgo primordial en lo tocante a la familia es el de una profunda desestructuración provocada por unas enormes transformaciones socioeconómicas que alteraron totalmente la estructura social.

\section{Cuenca}

El primer contexto es en las zonas rurales de la provincia de Cuenca. Los datos que comentaremos proceden de Reher (1988). Estas zonas se caracterizaban, tal y como se aprecia en el cuadro 3 , por el predominio incuestionable de la familia simple: los porcentajes de hogares simples entre el siglo XVIII y 1900 representaban entre 80 y $85 \%$ del total, llegando incluso en algunos momentos a niveles más altos. En consonancia con esa distribución porcentual de los hogares, tal y como se observa en el cuadro 4, el número medio de parientes corresidentes era exiguo. El corto número de los demás componentes hacía que las dimensiones medias del hogar nunca rebasaran los 3.63 miembros.

En relación con la cuestión de cómo afrontaban los ancianos la vejez en estas zonas rurales de Cuenca, adjuntamos dos cuadros que ratifican nuestras apreciaciones de que en el modelo familiar nuclear los viejos deben afrontar su situación en soledad. En el cuadro 5, los datos empíricos sobre el ciclo de vida de la familia vienen a indicar que conforme más viejo era el cabeza de familia mayor número de hogares solitarios había. Según se advierte, la preponderancia de los hogares simples disminuía a edades mayores en favor de los hogares solitarios y sin estructura. Los hogares solitarios, después de care-

CUADRO 3

Estructura del hogar en Cuenca en los siglos Xvin y XIX

\begin{tabular}{lrccc}
\hline & $S$. XVII & $1800-1850$ & $1851-1875$ & $1876-1900$ \\
\hline Solitarios & 11.9 & 9.8 & 9.9 & 10.9 \\
Sin estructura & 2.8 & 2.4 & 1.0 & 1.5 \\
Simples & 80.8 & 82.1 & 89.4 & 82.4 \\
Extensos & 4.1 & 4.9 & 4.1 & 4.2 \\
Múltiples & 0.4 & 0.8 & 0.5 & 1.0 \\
\hline
\end{tabular}

Fuente: Reher (1988: 6). 
CUADRO 4

Tamaño y composición del hogar en Cuenca. Siglos XVIII y XIX

\begin{tabular}{lcccc}
\hline & $S$. XVIII & $1800-1850$ & $1851-1875$ & $1876-1900$ \\
\hline Tamaño medio & 3.57 & 3.58 & 3.63 & 3.56 \\
Esposa & 0.71 & 0.77 & 0.77 & 0.78 \\
Hijos & 1.57 & 1.59 & 1.71 & 1.66 \\
Parientes & 0.09 & 0.09 & 0.08 & 0.09 \\
Sirvientes & 0.18 & 0.12 & 0.04 & 0.02 \\
\hline
\end{tabular}

Fuente: Reher (1988:154).

cer de notoriedad a lo largo de la mayor parte del ciclo vital familiar, adquirían mucho peso específico a partir del momento en que el vecino llegaba a la ancianidad. En el cuadro 6, relativo a la estructura por edad por estructura del hogar y que recoge los porcentajes de población de más de 50 años en cada tipo de hogar, se comprueba que cada tipo tenía una estructura de edades diferenciada. Los hogares solitarios tenían una pronunciada proporción de personas de más de 50 años, viudas o solteras: siete $u$ ocho de cada diez personas que vivían en tales hogares solitarios y sin estructura se inscribían en aquel tramo de edades. A su vez, los hogares extensos tenían una proporción bastante más alta de personas de más 50 años que los hogares nucleares porque su complejidad era provocada en la mayoría de los casos por la cohabitación de madres o padres viudos con algún hijo casado con o sin hijos.

CUADRO 5

Estructura del hogar según la edad del cabeza de familia en Cuenca. Siglos XVIII y XIX

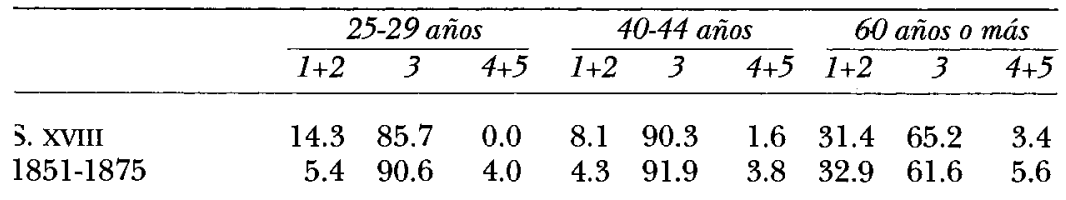

Nota: $1+2$ Solitarios y sin estructura; 3 Simples o nucleares; $4+5$ Extensos y núltiples.

Fuente: Reher (1988: 183). 


\section{CUADRO 6}

Estructura por edad según la estructura de los hogares en Cuenca. Siglos XVmI y XIX. Porcentajes de población de más de 50 años en cada tipo de hogares

\begin{tabular}{lccc}
\hline & $\begin{array}{c}\text { Solitarios y sin } \\
\text { estructura }\end{array}$ & Simples & $\begin{array}{c}\text { Extensos } \\
\text { múltiples }\end{array}$ \\
\hline $1750-1850$ & 73 & 14 & 32 \\
$1851-1900$ & 81 & 16 & 22 \\
\hline
\end{tabular}

Fuente: Reher (1988: 157).

\section{Norte y centro de Navarra}

El segundo contexto que presentamos es el de las zonas rurales del norte y del centro de Navarra en 1786, estudiadas por Mikelarena (1995). Esas zonas son las siguientes: Valles Meridionales (Vmer), Cuenca de Pamplona (Cuen), Valles Pirenaicos Occidentales (Proc), Zona Media Occidental (Meoc) y Zona Media Oriental (Meor). Tal y como se observa en el cuadro 7, en todas esas zonas predominaba la familia troncal: en todas ellas las proporciones de hogares complejos superaban $33 \%$, llegando a ser mucho más altas en algunas. Además, las proporciones de hogares solitarios oscilaban entre 4 y $6 \%$. Por lo tanto, en comparación con Cuenca, además de que en el norte y centro de Navarra la proporción de hogares complejos era mucho más alta, la proporción de hogares solitarios era sensiblemente inferior. También en comparación con Cuenca, el tamaño medio del hogar era, como se ve en el cuadro 8, sensiblemente más elevado en el norte de Navarra (zonas de Valles Merdionales, Cuenca de Pamplona y Pirineo Occidental) y algo menos elevado, aunque también bastante superior, en el centro de esta provincia (Zona Media Occidental y Zona Media Oriental). Las razones obedecían, según se puede ver en aquel cuadro, al lógico (por efecto de la mayor complejidad familiar) mayor número de parientes corresidentes, pero también al mayor número de sirvientes corresidentes y de hijos corresidentes. Respecto al mayor número de sirvientes, era superior en las zonas septentrionales de Navarra, quizás porque en ellas, en comparación con las zonas centrales, a las labores agrícolas se sumaban las ganaderas. De cualquier forma, resulta llamativo que el relativamente elevado número 
de parientes corresidentes coexista con un relativamente elevado, para los niveles españoles, número de domésticos, ya que en principio aquéllos aportarían mano de obra suplementaria. En cuanto al más elevado número de hijos corresidentes en relación con las cifras conquenses, la explicación radica en la combinación de los efectos sobre las cifras navarras de una mayor fecundidad matrimonial, una más baja mortalidad a edades tempranas, y una más tardía salida de los hijos del hogar paterno por ser la nupcialidad más tardía.

La cuestión del análisis empírico del ciclo vital de la familia en el norte y centro de Navarra en 1786 valiéndose de las listas de habitantes, expresadas en el cuadro 9 en el que se recogen las distribuciones de los hogares a distintas edades del cabeza de familia, merece un comentario preliminar. Es preciso tener en cuenta que las situaciones encarnadas por cabezas de familia de más de 60 años no reflejan claramente el ciclo de vida de la familia troncal, puesto que los individuos que llegaban a esa edad y continuaban en un grupo doméstico sstructurado troncalmente, en nuestra elaboración de los datos (que

XUADRO 7

istructura del hogar en el norte y centro de Navarra en 1786

\begin{tabular}{lrrrrr}
\hline & Vmer & Cuen & Proc & Meoc & Meor \\
\hline olitarios & 5.3 & 5.1 & 6.1 & 4.2 & 4.7 \\
in estructura & 2.0 & 1.4 & 1.5 & 1.1 & 1.0 \\
imples & 58.7 & 48.6 & 45.2 & 59.5 & 60.6 \\
xtensos y múltiples & 33.9 & 44.9 & 47.1 & 35.2 & 33.7 \\
\hline
\end{tabular}

Fuente: Mikelarena (1995: 245),

\section{UADRO 8}

amaño medio del hogar y composición en el norte y centro de Navarra 11786

\begin{tabular}{lccccc}
\hline & Vmer & Cuen & Proc & Meoc & Meor \\
\hline \multirow{3}{*}{ imaño medio } & 5.27 & 5.79 & 5.80 & 4.88 & 4.74 \\
ijos & 2.44 & 2.18 & 2.18 & 2.01 & 1.87 \\
rientes & 0.71 & 1.04 & 1.27 & 0.70 & 0.63 \\
vientes & 0.52 & 0.70 & 0.53 & 0.34 & 0.40 \\
\hline
\end{tabular}

Fuente: Mikelarena (1995: 268). 
parte de considerar, por razones de homogeneización estadística y en consonancia con las costumbres, siempre como cabeza de familia al núcleo conyugal más:joven, esto es el núcleo conyugal heredero, en caso de coexistir personas casadas o viudas de dos niveles generacionales) quedaban subsumidos en hogares encabezados por individuos más:jóvenes. Por lo tanto, los casos de hogares cuyo cabeza de familia superaba los 60 años se corresponden con casos de hogares de campesinos arrendatarios o:jornaleros o de artesanos que seguían pautas de estructuración familiar propias del modelo familiar nuclear y no del troncal. Bajo esa advertencia, el descenso de hogares complejos desde proporciones superiores a $50 \%$, e incluso a 60 y a $70 \%$ en algunas comarcas, cuando el cabeza de familia tenía entre 20 y 29 años, hasta niveles en torno a 15 o $20 \%$ cuando el cabeza de familia tenía más de 60 y, a la inversa, el destacado crecimiento de las proporciones de los hogares simples, así como el gran incremento del peso porcentual de los hogares solitarios, no constituye una refutación de nuestra aseveración de que los viejos de las familias troncales envejecían acompañados de sus familias, sino que es sólo un error de perspectiva.

\section{CUADRO 9}

Estructura del hogar por edad del cabeza de familia en el norte y centro de Navarra en 1786

\begin{tabular}{|c|c|c|c|c|c|c|c|c|c|}
\hline & \multicolumn{3}{|c|}{ Vmer } & \multicolumn{3}{|c|}{ Cuen } & \multicolumn{3}{|c|}{ Proc } \\
\hline & $20-29$ & $40-49$ & $\begin{array}{c}\text { Más } \\
\text { de } 60\end{array}$ & $20-29$ & $40-49$ & $\begin{array}{c}\text { Más } \\
\text { de } 60\end{array}$ & $20-29$ & 40.49 & $\begin{array}{c}\text { Más } \\
\text { de } 60\end{array}$ \\
\hline \multirow{6}{*}{$\begin{array}{l}\text { Solitarios } \\
\text { Sin estructura } \\
\text { Simples } \\
\text { Extensos y } \\
\text { múltiples }\end{array}$} & 2.1 & 1.4 & 2.9 & 3.8 & 4.8 & 14.3 & 3.4 & 2.9 & 12.5 \\
\hline & 4.2 & 0.9 & 2.3 & 1.0 & 1.4 & 1.4 & 2.3 & 0.9 & 0.0 \\
\hline & 36.9 & 64.3 & 72.7 & 23.1 & 55.0 & 67.1 & 17.2 & 51.2 & 72.2 \\
\hline & & & & & & & & & \\
\hline & 56.8 & $\begin{array}{l}33.4 \\
\text { Meoc }\end{array}$ & 22.1 & 72.1 & $\begin{array}{l}38.8 \\
\text { Meor }\end{array}$ & 17.1 & 77.0 & 44.9 & 15.3 \\
\hline & $20-29$ & $40-49$ & $\begin{array}{c}\text { Más } \\
\text { de } 60\end{array}$ & $20-29$ & $40-49$ & $\begin{array}{l}\text { Más } \\
\text { de } 60\end{array}$ & & & \\
\hline Solitarios & 3.0 & 1.7 & 9.0 & 0.4 & 2.7 & 8.6 & & & \\
\hline Sin estructura & 1.0 & 0.9 & 3.3 & 1.3 & 0.9 & 1.7 & & & \\
\hline Simples & 33.1 & 70.2 & 72.5 & 44.5 & 68.2 & 77.6 & & & \\
\hline $\begin{array}{l}\text { Extensos y } \\
\text { múltiples }\end{array}$ & 62.9 & 27.2 & 15.1 & 53.7 & 28.1 & 12.1 & & & \\
\hline
\end{tabular}

Fuente: Mikelarena (1995: 275-276). 
Una prueba de los sesgos implícitos en el cuadro 9, así como una corroboración de que los viejos de estas sociedades caracterizadas por el predominio de la familia troncal envejecían mayoritariamente en el seno de sus mismas familias, precisamente en las fases en que dichas familias volvían a ser complejas, la tenemos en la información de los siguientes cuadros.

Según el cuadro 10, en el norte y centro de Navarra en 1786 la población de más de 50 años se localizaba mayoritariamente en los hogares complejos: en las cinco comarcas diferenciadas, más de $50 \%$ de aquella población habitaba en hogares extensos y múltiples, alcanzándose dos tercios en algunas zonas.

CUADRO 10

Porcentajes de población mayor de 50 años sobre el total de población mayor de 50 años según el tipo de hogar en el norte y centro de Navarra en 1786

\begin{tabular}{lrrrrr}
\hline & Vmer & Cuen & Proc & Meoc & Meor \\
\hline Solitarios y sin estructura & 4.6 & 3.4 & 3.4 & 4.8 & 4.5 \\
Simples & 43.1 & 30.8 & 28.8 & 36.0 & 41.2 \\
Extensos y múltiples & 52.2 & 65.8 & 67.8 & 59.2 & $\mathbf{5 4 . 3}$ \\
\hline
\end{tabular}

Fuente: Mikelarena (1995: 270).

Lo apuntado en el cuadro anterior se ratifica en el cuadro 11 , donde se presentan las cifras medias de individuos mayores de 50 años residentes en cada tipo de hogar. En la Navarra troncal patrilocal los ıogares complejos llegaban a tener unas cifras en torno a los 1.3-1.5 ndividuos mayores de 50 años, los cuales duplican las que se constaan en los hogares solitarios y sin estructura y en los hogares simples.

\section{IUADRO 11}

Júmero de individuos mayores de 50 años que vivían en cada tipo de hogar n el norte y centro de Navarra en 1786

\begin{tabular}{lccccc}
\hline & Vmer & Cuen & Proc & Meoc & Meor \\
\hline olitarios y sin estructura & 0.601 & 0.484 & 0.439 & 0.713 & 0.578 \\
imples & 0.700 & 0.590 & 0.640 & 0.480 & 0.500 \\
xtensos y múltiples & 1.467 & 1.367 & 1.440 & 1.335 & 1.184 \\
\hline
\end{tabular}

Fuente: Mikelarena (1995: 272). 
Por último, en el cuadro 12 presentamos las proporciones de hogares dentro de cada tipo de hogar con población de más de 50 años. Como se ve, en la inmensa mayoría de los hogares complejos alguna persona tenía una edad superior a la cincuentena de años. Los porcentajes de hogares complejos con esa población duplicaban los de los hogares solitarios y sin estructura y de los hogares simples.

CUADRO 12

Proporciones de hogares dentro de cada tipo de hogar con población mayor de 50 años en el norte y centro de Navarra en 1786

\begin{tabular}{lccccc}
\hline & Vmer & Cuen & Proc & Meoc & Meor \\
\hline Solitarios y sin estructura & 44.5 & 43.7 & 39.4 & 58.7 & 55.4 \\
Simples & 46.5 & 40.5 & 42.7 & 34.9 & $\mathbf{3 4 . 6}$ \\
Extensos y múltiples & 87.8 & 86.7 & 88.7 & 87.4 & 84.2 \\
\hline
\end{tabular}

Fuente: Mikelarena (1995: 273).

\section{Pamplona}

Pamplona, la capital de Navarra, contaba en 1786 con 14066 habitantes y era su principal núcleo urbano; el segundo, Tudela, contaba con 7572 habitantes y era también la principal ciudad del contexto vasconavarro. En la mitad norte de España solamente otros seis núcleos poseían mayor volumen poblacional.

La estructura económica de Pamplona puede reconstruirse con las informaciones del censo nominal de 1786 . Según las profesiones declaradas por los cabezas de familia, $26 \%$ de los hogares estaba vinculado al trabajo de la tierra: $22.2 \%$ como labradores, en su mayor parte renteros, y 3.8 como jornaleros agrícolas. Otro $41.8 \%$ de los cabezas de familia se ocupaba en ejercicios artesanales. Entre estos artesanos un elevado número se centraba en algunas actividades concretas: así había 120 sastres, 85 pelaires [cardadores de paños], 76 zapateros, 70 chocolateros, 70 carpinteros, 63 albañiles, 37 tejedores, 35 basteros, 27 cordeleros, 21 plateros, 21 cuberos, 20 cerrajeros, 19 canteros, 19 calceteros, 17 boteros, 16 peineros, 14 guanteros, 13 impresores, 13 cordoneros, 12 esquiladores, 11 fajeros, 10 cuchilleros, etc. Ello demuestra que gran parte de la artesanía pamplonesa traspasaba el mer- 
cado urbano y que nutría en una medida difícil de precisar la demanda rural del resto de Navarra, gracias al amparo de los privilegios monopolísticos (como el de exclusividad de trabajo y el de inspección y aprobación de los artículos extranjeros) de los gremios navarros, que no se derogarian hasta que las Cortes navarras de 1817-1818 decretaron la libertad de trabajo y de competencia.

Comenzando por la estructura familiar pamplonesa, el rasgo más señero de las estructuras de los 2760 hogares de la ciudad en 1786 era la elevada, en términos relativos, complejidad familiar. Tal y como se aprecia en el cuadro 13, la proporción de los hogares complejos era del $18.6 \%$ del total; los hogares solitarios alcanzaban 12.6 por ciento.

CUADRO 13

Estructura del hogar en Pamplona en 1786

\begin{tabular}{lcc}
\hline & Números absolutos & Porcentaje \\
\hline Solitarios & 347 & 12.6 \\
Sin estructura & 85 & 3.0 \\
Simples & 1814 & 65.7 \\
Extensos & 370 & 13.4 \\
Múltiples & 144 & 5.2 \\
Total & 2760 & 100.0 \\
\hline
\end{tabular}

Fuente: Mikelarena (1994: 131).

La proporción mencionada de hogares complejos no es excesiva en comparación con los valores del mundo rural troncal navarro, pero sí destaca si la cotejamos con los valores de otras ciudades españolas. Las motivaciones de esa relativamente alta complejidad familiar estribaban en la vigencia de la patrilocalidad y de las pautas troncales de estructuración familiar ya que en $60.1 \%$ de los hogares complejos se constata la existencia de corresidencia de dos unidades conyugales, presentes o rotas, de diferente nivel generacional unidas con vínculos paternofiliales. Por otra parte, el análisis por sectores sociales demuestra que las soluciones familiares complejas poseían una base social multisectorial: $20.2 \%$ de los hogares de artesanos era de tipo complejo, lo mismo que $23.6 \%$ de los hogares de labradores, 28.5 de profesionales liberales, 25.8 de funcionarios y 13.4 de los hogares de :jornaleros. Con todo, la mayor frecuencia de cohabitación de padres e hijos casados o viudos en un mismo hogar entre los labradores y los profe- 
sionales liberales viene a indicar que entre ellos la complejidad familiar se debía en una medida mayor al seguimiento de esquemas de patrilocalidad. Por contra, entre los artesanos y los jornaleros agrícolas la complejidad familiar estaba ocasionada muy frecuentemente por la corresidencia en un mismo hogar de una unidad conyugal y de parientes solteros colaterales (hermanos o cuñados de algún miembro de aquélla, sobrinos, etcétera).

¿En qué hogares residían los ancianos de Pamplona? Para responder a esa pregunta, en el cuadro 14 se presenta, por un lado, la distribución de los mayores de 60 años en los distintos tipos de hogares, y por otro, el número medio de personas de más de 60 años en cada tipo de hogar. Según se advierte, la mayoría de los ancianos residía en hogares complejos. No obstante, en comparación con los niveles observados en los contextos rurales troncales navarros, en Pamplona la presencia de ancianos en hogares solitarios era mucho más alta, y bastante más baja en hogares complejos. Desde otro ángulo, mientras en los hogares solitarios y sin estructura pamploneses vivía una media de 0.305 personas ancianas, en los hogares simples residía 0.168 y en los complejos nada menos que 0.630 . Por lo tanto, si bien en Pamplona la proporción de personas de la tercera edad que vivían la vejez en soledad era superior a la de los ámbitos rurales navarros, no cabe duda de que muchos ancianos, desde luego muchos más que en las zonas de familia nuclear, afrontaban la vejez en compañía de sus familias.

Por último, en el cuadro 15 presentamos la distribución de las personas de más de 60 años por sexos y según su relación con el cabeza de familia. Tal y como se percibe, la mitad de las personas de más de 60 años eran cabezas de familia, en aproximadamente la mitad de los casos de hogares solitarios. Ese porcentaje llegaba a dos tercios en-

CUADRO 14

Distribución de los mayores de 60 años en los distintos tipos de hogares y número medio de personas de más de 60 años en cada tipo de hogar

\begin{tabular}{lcc}
\hline & Distribución & Número medio \\
\hline Solitarios y sin estructura & 17.3 & 0.305 \\
Simples & 40.1 & 0.168 \\
Extensos y múltiples & 42.6 & 0.630 \\
\hline
\end{tabular}

Fuente: Mikelarena y Erdozáin, 1998. 
tre los hombres y a sólo un tercio entre las mujeres, si bien entre éstas $10.4 \%$ eran esposas del cabeza de familia. Por su parte, casi una tercera parte de los ancianos eran parientes del cabeza de familia, en su mayoría unidos a él por vínculos de paternidad. Los casos de ancianos que eran sirvientes o huéspedes eran en cambio residuales, algo perfectamente normal.

CUADRO 15

Distribución de las personas de más de 60 años según su relación con el cabeza de familia

\begin{tabular}{lrrr}
\hline & Hombres & Mujeres & Total \\
\hline Cabeza & 64.4 & 34.3 & 49.3 \\
Esposa & 0.0 & 20.6 & 10.4 \\
Hijos & 0.0 & 0.0 & 0.0 \\
Parientes & 27.5 & 37.6 & 32.6 \\
Sirvientes & 2.2 & 4.5 & 3.4 \\
Huéspedes & 5.6 & 2.9 & 4.2 \\
Total & 99.7 & 99.9 & 99.9 \\
\hline
\end{tabular}

Fuente: Mikelarena y Erdozáin (1998).

\section{Bilbao}

El caso de Bilbao representa un contexto urbano en un tiempo histórico marcado por importantes transformaciones socioeconómicas que acaecen en la ciudad y su entorno, la Ría de Bilbao, a lo largo de a segunda mitad del siglo XIX y las primeras décadas del XX.

Los datos que se desprenden de los padrones de población de 1825,1900 y $1935,{ }^{1}$ son altamente representativos del proceso de cre:imiento económico y de modernización sociodemográfica que vivió

${ }^{1}$ Para 1825 se utilizó el Censo de Policía; para 1900 y 1935 los Padrones ১unicipales de Bilbao. El estudio al que nos referimos se realizó a partir de una nuestra hecha de forma aleatoria con unos niveles de error de $\pm 2 \%$ y con una confiana de $99.9 \%$. De esta muestra original se seleccionaron aquellos individuos mayores de 10 años junto con todos sus familiares y corresidentes, independientemente de si enían la jefatura del hogar o no. El universo fue de 205 ancianos en 1825 , de 309 en 900 , y de 440 en 1935, prescindiendo de cuarteles, conventos u otras cédulas olectivas. 
esta ciudad a lo largo de un siglo. Si en 1825 , aún en un contexto de Antiguo Régimen, Bilbao se nos presenta como centro rector de las actividades económicas y sociales de ámbito regional, en 1900 la ciudad ya se había constituido en capital financiera y comercial de la expansión industrial que se desarrolló no sólo en el País Vasco, sino en todo el norte de España. Tres décadas más tarde, en 1935, Bilbao era la ciudad industrial por excelencia de España, en la que se concentraba una elevada proporción de los capitales del país.

Las listas nominales de población de estos años nos permiten una primera aproximación a las modalidades de corresidencia de los mayores en el Bilbao preindustrial, y podemos comprobar los cambios habidos en esta ciudad que se va afianzando como punto de referencia ineludible en el proceso de industrialización de España (PérezFuentes y Pareja, 1997). Los datos sobre la morfología de los hogares donde vivían los ancianos son una significativa muestra de cómo el vínculo establecido entre vejez-soledad-desatención como un elemento consubstancial al proceso de modernización es más una proyección desde el presente que una realidad del pasado.

En primer lugar, el peso de los mayores de 60 años en el conjunto de la población bilbaína era un reflejo de los cambios sociodemográficos que vivía la ciudad en las últimas décadas del siglo XIX. El impacto de las intensas inmigraciones de población joven atraídas por el acelerado crecimiento económico de Bilbao y su hinterland, redujo el peso de la población mayor de 60 años hasta niveles bastante inferiores a los de la ciudad del Antiguo Régimen. Pese a la persistente caída de las tasas brutas de mortalidad, la predominancia de la población en edad de trabajar era constante debido a la enorme capacidad de atracción de la ciudad para los emigrantes. Ya en la década de los ochenta, el peso de los mayores de 60 años había descendido hasta $5.4 \%$ sobre el total de la población, porcentaje inferior no sólo a la media de España (7.5\%) sino también al de las demás capitales de provincia (Gómez, 1896). En 1900, como puede verse en el cuadro 16 , el peso de la población mayor de 60 años alcanza sus mínimos (5.2\%) como consecuencia de las inmigraciones y de los cambios producidos en los comportamientos vitales de la población.

Tres décadas más tarde, en esta ciudad ya plenamente representativa de la moderna sociedad industrial -en la que ya habían disminuido considerablemente las tasas de mortalidad general y de fecundidad propias de las primeras fases de la industrialización- el peso de la población mayor de 60 años había alcanzado de nuevo los niveles de 1825 . 
CUADRO 16

Porcentaje de población mayor de 60 años

\begin{tabular}{ccc}
\hline & Bilbao & San Salvador del Valle (Vizcaya) \\
\hline 1825 & 7.2 & \\
1877 & & 4.18 \\
1887 & 5.2 & 1.97 \\
1900 & & 2.28 \\
1910 & & 3.98 \\
1920 & & 5.18 \\
1930 & 7.6 & 6.57 \\
1935 & &
\end{tabular}

Fuente: Para Bilbao, Pérez-Fuentes y Pareja (1997: 82). Para San Salvador del Valle, datos elaborados por los autores a partir de los censos y padrones de población.

Otro rasgo a destacar en lo que afecta a la población mayor de 60 años es el desequilibrio en la razón de masculinidad en los efectivos de este grupo de población. Sabemos que ésta es una característica de la demografia urbana europea que se manifiesta de manera especialmente aguda en los grupos de mayor edad a consecuencia de una mayor esperanza de vida. Pero tal vez este fenómeno sea especialmente notable en Bilbao, ${ }^{2}$ donde un sector de servicios fuertemente desarrollado, especialmente el servicio doméstico -la más alta proporción de criadas en el conjunto de las ciudades españolas, una por cada once habitantes en 1887 (Gómez, 1896)-, atraía a una numerosa población femenina vizcaína y de las provincias limítrofes. Este desequilibrio en el balance entre los sexos originado por las características del mercado de trabajo disminuía en la medida en que las mujeres sobrepasaban la edad de contraer nupcias (Pérez-Fuentes y Arbaiza, 1995). Sin embargo, el hecho de que las mujeres se mostrasen más longevas que los hombres, junto con la persistencia de mujeres mayores en el servicio doméstico ocasionaba unos índices de masculinidad muy bajos. ${ }^{3}$ No hay duda de que esta desproporción en los efectivos de población mayor de 60 años

${ }^{2}$ Sólo las ciudades de Santander, Coruña y Pontevedra superaban en 1887 las bajas razones de masculinidad de Bilbao. En estos casos, es el fenómeno de la emigración masculina la clave explicativa de los desequilibrios poblacionales entre los sexos.

${ }^{3}$ Los datos del cuadro 17 presentan grandes variaciones en la razón de masculinidad que no pueden ser debidas a la evolución de la esperanza de vida de hombres y mujeres. Una vez más el factor migratorio es la clave explicativa. 
es reflejo de una mayor capacidad de supervivencia, pero queremos insistir en que la inmigración de mujeres a la ciudad es un factor que afectó, años después, a las ratios de masculinidad en esta fase del ciclo vital y a las condiciones de vida de las ancianas.

CUADRO 17

Razón de masculinidad en la población mayor de 60 años en Bilbao

\begin{tabular}{llll}
\hline Edad & 1825 & 1900 & 1935 \\
\hline $60-64$ & 73.13 & 63.16 & 66.02 \\
$65-69$ & 67.12 & 60.00 & 63.51 \\
$70-74$ & 79.10 & 56.10 & 80.00 \\
$75-79$ & 84.00 & 44.44 & 34.21 \\
Más de 80 & 54.29 & 61.54 & 28.57 \\
\hline
\end{tabular}

Fuente: Pareja y Arbaiza (1995: 212).

Lo que nos interesaba saber era ¿cómo afectaron estos grandes cambios que experimentó la ciudad a las pautas de corresidencia de los mayores? Sabemos que en la sociedad preindustrial en la Europa occidental la familia tuvo un papel muy importante en la atención y cuidados de las personas mayores, pese a la predominancia del sistema familiar nuclear, y Bilbao no es una excepción.

El sistema familiar -definido tanto por los comportamientos nupciales como por las pautas de estructuración y composición familiar- de Bilbao responde a las características del modelo de familia descrito para las regiones de Europa noroccidental (Laslett, 1972 y Hajnal, 1965), y además, la ciudad presenta una enorme estabilidad a lo largo de esta centuria en lo que a modelos familiares se refiere (Pérez-Fuentes y Arbaiza, 1995). Pese a las profundas transformaciones que se vivieron en este municipio y en su hinterland, el predominio de la familia nuclear, la elevada edad al contraer matrimonio, así como los altos niveles de celibato definitivo, persistieron e incluso se acentuaron entre 1825 y $1935 .{ }^{4}$

No parecería desacertado pensar que un centro urbano tan pujante como Bilbao ofreciese a la población la posibilidad de crear nuevos núcleos familiares, por contraposición al medio rural vasco donde his-

${ }^{4} \mathrm{El}$ porcentaje de población que quedaría soltera se mantiene en torno a $12-17 \%$ para las mujeres y 8-10\% en los hombres (Pérez-Fuentes y Arbaiza, 1995). 
tóricamente el sistema troncal restringía las posibilidades de contraer matrimonio. Pero lo cierto es que la capital nos presenta un modelo de baja presión demográfica con rasgos más pronunciados y persistentes que el conjunto de la región que era predominantemente rural hasta 1887. Tradicionalmente, el modelo de baja presión se ha venido relacionando con la existencia de una tipología familiar troncal. Sin embargo, el caso de Bilbao es un ejemplo de cómo una nupcialidad tardía y restringida también puede estar sostenida por una estructuración del hogar de tipo nuclear (Pérez-Fuentes y Arbaiza, 1995).

$\mathrm{El}$ hecho de que las características del modelo familiar prácticamente no varíen en sus rasgos básicos y que la familia nuclear se mantenga como modelo predominante a lo largo de los siglos XIX y XX, nos muestra que este modelo de familia opera, una vez más, con una elevada capacidad de adaptación a las grandes transformaciones que se producen de puertas afuera de los hogares, y que permite la reproducción social bajo circunstancias socioeconómicas muy diferentes. ${ }^{5}$

La cuestión era comprobar si a pesar de la estabilidad de las estructuras familiares tomadas en su conjunto, las relaciones de solidaridad intergeneracionales se vieron afectadas por los cambios. Sabemos que en esta fase del ciclo vital, las quiebras en el núcleo familiar originadas por la defunción del cónyuge y por el abandono del hogar por parte de los hijos, o la opción del celibato, dibujan un panorama dificil de resolver en el marco de un sistema familiar nuclear, y más aún, en una coyuntura de fuerte movilidad de la población.

En Bilbao la posibilidad de vivir en un hogar de estructura nuclear fue la opción más habitual para los hombres mayores de 60 años a lo largo de todo el periodo estudiado, sin que apenas hubiese cambios en las modalidades de los hogares en los que éstos vivían. En torno a $60 \%$ de los varones estaba en hogares nucleares, mientras que $30 \%$ vivía en familias complejas, sin que el aumento de la esperanza de vida y los cambios habidos en la composición socioeconómica y demográfica de la población aumentasen significativamente los niveles de soledad de los ancianos. Vivir solos o sin parientes era una posibilidad que, aun en el peor de los casos, afectaba a menos de 10 por ciento.

Sin embargo sí pudimos advertir cambios importantes en las formas en que las mujeres afrontaban esta fase del ciclo vital. La probabilidad

${ }^{5}$ La proporción de familias nucleares era de $73 \%$ en $1825 ; 71 \%$ en 1900 y $68 \%$ en 1935. A lo largo de la centuria aumentaron los hogares complejos de $17 \%$ en 1825 a 23\% en 1935 y se redujeron a la mitad los solitarios (Pérez-Fuentes y Arbaiza, 1995: 272). 
de vivir en hogares nucleares, siempre muy inferior a la de los hombres por las mayores posibilidades de quiebra del núcleo familiar originadas por la muerte del marido, aumentaron a lo largo del siglo, al incrementarse también la esperanza de vida de los varones. Ycomo era de esperar, también crecieron las posibilidades de que las mujeres residiesen en un hogar complejo al tener una esperanza de vida más alta.

Pero uno de los resultados más interesantes de este estudio fue la diferencia tan pronunciada que existía entre el porcentaje de hombres y de mujeres en hogares solitarios o sin parientes, así como el sentido inverso de la evolución de los datos. Si en la ciudad preindustrial, en 1825, una cuarta parte de las ancianas vivía en hogares solitarios o con personas sin relación de parentesco directo o reconocible en los padrones, en el caso de los hombres la proporción no alcanzaba 7 por ciento.

En el cuadro 18 se aprecia claramente cómo en el fin de siglo, el impacto de los cambios socioecónomicos aumentó ligeramente la soledad de los ancianos tanto en el caso de las mujeres como en el de los hombres. Sin embargo, no se trata de un fenómeno sostenido en el tiempo, sino que parece más bien vinculado a una determinada coyuntura histórica de aceleradas transformaciones. De tal manera que en el padrón de 1935, el porcentaje de mujeres en situación de soledad se había reducido considerablemente hasta niveles inferiores al de los varones, en favor de la corresidencia con parientes. Ya fuera en hogares nucleares, en hogares complejos, o con algún tipo de parentesco entre sus miembros, la cuestión es que sólo $7 \%$ de las mujeres mayores se encontraban viviendo solas o sin familiares en el hogar.

CUADRO 18

Estructuras de los hogares en los que viven los mayores de 60 años

\begin{tabular}{|c|c|c|c|c|c|c|}
\hline & \multicolumn{2}{|c|}{1825} & \multicolumn{2}{|c|}{1900} & \multicolumn{2}{|c|}{1935} \\
\hline & Hombres & $\overline{\text { Mujeres }}$ & Hombres & Mujeres & Hombres & Mujeres \\
\hline Solitarios* & 6.8 & 24.0 & 10.3 & 25.4 & 9.7 & 7.3 \\
\hline Sin estructura & 4.6 & 6.0 & 1.7 & 3.1 & 3.6 & 5.8 \\
\hline Nucleares & 56.8 & 30.8 & 56.9 & 33.7 & 57.0 & 38.2 \\
\hline Extensos y múltiples & 31.8 & 39.9 & 31.0 & 37.8 & 29.7 & 48.7 \\
\hline
\end{tabular}

* Además de los ancianos en hogares solitarios, están incluidos los que viven en calidad de huéspedes de otras familias con las que no tienen ninguna relación de parentesco. En este caso, las estructuras familiares de estos hogares no han sido consideradas.

Fuente: Pérez-Fuentes y Arbaiza (1997: 88). 
El hecho de que los niveles de soledad de las mujeres mayores sean superiores es un fenómeno común a todas las poblaciones estudiadas (Wall, 1991). Obviamente, el diferencial de la esperanza de vida es determinante, pero esta variable demográfica puede reforzar o contrarrestar diferentes opciones de corresidencia entre hombres y muijeres ancianas que vienen condicionadas por otros factores externos al sistema familiar. El acceso a los recursos, sobre todo considerando a la estructuración de los mercados de trabajo modernos y los movimientos migratorios que ocasionan, ijuega un papel importante a la hora de analizar las diferentes formas de corresidencia de mujeres y de hombres en esta fase del ciclo vital. Sería necesario abundar en enfoques analíticos que nos permitiesen la reconstrucción de las trayectorias vitales de los ancianos para aproximarnos a las consecuencias generadas por determinadas decisiones tomadas en otros momentos de sus vidas.

En el caso de Bilbao, como en otras ciudades, el aumento de la dependencia de las mujeres mayores respecto de la familia no parece ser fruto sólo del aumento de la esperanza de vida. Hay todo un proceso de abandono de las actividades remuneradas y de aumento de las dificultades para acceder a los nuevos empleos que intensificaría su dependencia económica. Esta mayor dependencia económica, oriz̧inada por la extrema división sexual del trabajo de las sociedades industriales, discurre de manera paralela a una mayor protección de las nujeres, también, en esta fase del ciclo vital. Lo cierto es que los nivees de actividad de las mujeres en 1825 eran considerablemente más levados que en 1900 , y sobre todo que en $1935 .{ }^{6}$ Aunque buena pare de los trabajos estuviesen situados en bajos niveles salariales y de caificación, el hecho es que el modelo de género que se establece en

${ }^{6}$ En 1825 casi la totalidad de las mujeres mayores de 60 años aparece con una ctividad reconocida, y aunque se trata de datos relativamente fiables son indicativos le un fenómeno ya conocido: la mayor actividad de las mujeres en las sociedades ıreindustriales. La drástica desaparición de las mujeres del mercado de trabajo, tal y omo puede verse en los padrones de 1900, tiene que ver con la decadencia de ectores tradicionales de la economía como la agricultura, y sobre todo la producción rtesanal, donde la presencia de las mujeres era considerable. Era frecuente, además, ue el fin de su vida laboral, desarrollada con mayor o menor intensidad, fuese arejo a la muerte. La evolución de la tasa de actividad de las mujeres de 40-59 años es uy significativa. En 1825: $73 \%$; en 1900: $23.5 \%$; en 1935: $13.6 \%$. En el caso del rupo de más de 60 años de edad la evolución de las tasas de actividad continúa en la iisma tónica del grupo de edad anterior: 1825: 71\%; 1900: 20\%; 1935: 8.8\% (Pérezuentes y Arbaiza, 1995: 303). 
las sociedades industriales (y Bilbao es un excelente ejemplo), refuerza los lazos dentro del núcleo familiar, tal vez más aún que en el pasado, en lo que respecta a las mujeres.

Sabemos que a lo largo del siglo XIX existió en Bilbao una fuerte demanda de mano de obra femenina, especialmente en el servicio doméstico. También sabemos que se trataba de una modalidad de inserción socioeconómica de población femenina rural que generaba altas posibilidades de soltería definitiva, y que éstas se traducían en una vejez sin cónyuge o hijos a su lado. Tal vez sea éste un factor explicativo de la elevada proporción de ancianas que vivían en hogares solitarios o sin vínculos familiares.

Por eso es muy importante considerar el comportamiento de la nupcialidad como un factor explicativo para abordar las formas de corresidencia de los mayores. Y lo cierto es que a pesar del fuerte crecimiento económico, las condiciones para la formación de nuevos hogares en Bilbao no mejoraron a lo largo del siglo. No sólo existían dificultades de tipo económico (bajos salarios, escasez de viviendas, etc.), sino también factores sociales y culturales derivados del fenómeno inmigratorio que segmentaba muy particularmente los mercados matrimoniales de esta ciudad (Pérez-Fuentes y Arbaiza, 1995). Esta baja intensidad de la nupcialidad determinaba las posibilidades futuras de residir a partir de los 60 años en una modalidad de hogar o en otra. Los altos niveles de celibato definitivo, como uno de los rasgos del sistema nupcial de esta ciudad, llevó a la décima parte de las ancianas a permanecer solteras, e incluso ocasionó que en $1900 \mathrm{su}$ proporción se elevase hasta casi 15 por ciento.

Ahora bien, no sabemos hasta qué punto los mayores niveles de soledad de las mujeres entre 1825 y 1900 tuvieron que ver con la soltería, y ésta, a su vez, con determinadas trayectorias laborales o de estatus económico. Y tampoco sabemos si aun estando ante fenómenos de la misma intensidad -el de la soledad de las ancianas en 1825 y en 1900-, éstos son de naturaleza distinta. Contestar a estas preguntas hubiese requerido aproximarse con más precisión al perfil de las mismas, pero el nivel de la muestra que se utilizó no nos ha permitido comprobar nuestras hipótesis.

Pero además, la edad de acceso al matrimonio de los hijos y los niveles de celibato de los mismos son factores que también habría que tener en cuenta al abordar las modalidades de corresidencia de los mayores. Porque es obvio que la elevada edad al contraer matrimonio retrasa el abandono del hogar por parte de los hijos y, conse- 
CUADRO 19

Estado civil de los mayores de 60 años en Bilbao

\begin{tabular}{lccccccc} 
& \multicolumn{3}{c}{ Hombres } & & \multicolumn{3}{c}{ Mujeres } \\
\cline { 2 - 4 } & Solteros & Casados & Viudos & & Solteras & Casadas & Viudas \\
\hline & & & & & & \\
1825 & 7.7 & 64.1 & 28.2 & 7.6 & 38.9 & 53.4 \\
1900 & 8.5 & 57.5 & 34.0 & 14.6 & 29.6 & 55.8 \\
1935 & 9.8 & 58.2 & 32.0 & 9.7 & 31.3 & 59.0 \\
\hline
\end{tabular}

Fuente: Pérez- Fuentes y Paraja (1997: 85).

cuentemente, incrementa las probabilidades de que los sexagenarios casados o viudos tengan algún descendiente soltero en el hogar. ${ }^{7}$

En el caso de Bilbao podemos concluir que, a lo largo de un siglo de grandes transformaciones, los lazos de solidaridad familiar, en lo que respecta a las pautas de corresidencia y la morfología de los hogares, no se vieron substancialmente alterados con la modernización. Sin embargo, también es cierto que determinadas coyunturas del proceso de crecimiento económico se tradujeron en un incremento de los niveles de soledad de los mayores. Desde una perspectiva de más largo plazo, la centuria se salda con un reforzamiento de la protección familiar respecto a las ancianas, si bien aumentan ligeramente los niveles de soledad de os varones, invirtiéndose los patrones de la ciudad premoderna.

Los datos refuerzan la idea de que la industrialización y la urbaniación no aumentaron de manera lineal la soledad de las personas nayores y que la familia nuclear en Europa se flexibilizó para atender as necesidades de sus ancianos en un nuevo contexto de mayor espeanza de vida de hombres y mujeres y de mayor dependencia econónica de estas últimas.

\section{ian Salvador del Valle (Vizcaya)}

، este proceso de crecimiento y modernización económica de Bilbao los municipios situados en su Ría no es ajena la coyuntura excepcio-

\footnotetext{
${ }^{7} \mathrm{La}$ edad media al contraer matrimonio era alta en esta ciudad. En 1825 era de 7.4 años para los hombres y de 27.6 para las mujeres; en 1900 los hombres se casaban una edad media de 27.3 años y las mujeres de 25.2; en 1930 la edad era de 28 años tra los hombres y 25.5 para las mujeres (Pérez- Fuentes y Arbaiza, 1995: 299 y 303).
} 
nalmente favorable para la explotación del mineral de hierro que se encontraba en el anticlinal de Bilbao.

San Salvador del Valle es el municipio más representativo de la zona minera de Vizcaya y se encuentra a tan sólo $15 \mathrm{~km}$ de la capital. Entre 1877 y 1887 su población creció en más de $400 \%$, coincidiendo con el boom de la explotación-exportación de mineral de hierro. Ocurrió que pequeños municipios de base agrícola o de economía mixta, habitados por propietarios o arrendatarios y con bajos niveles de asalarización, sufrieron una radical transformación en estos años. Se convirtieron de la noche a la mañana en municipios deijornaleros cuyos patrones de inmigración estaban estrechamente relacionados con la naturaleza y la evolución de la producción del mineral. ${ }^{8}$

En este contexto de llegada masiva de mano de obra a las minas de hierro vizcaínas, el peso de la población mayor de 60 años perdió relevancia (véase el cuadro 16). Poca cabida tenían los mayores en esta sociedad de jóvenes inmigrantes, hasta el punto de que en 1887 había tan sólo 1.97 ancianos por cada 100 habitantes. Años después, cuando la minería empezó a decaer y dejó de ser un mercado de trabajo atractivo -por su inestabilidad y los bajosijornales en relación con los empleos industriales- la proporción de los mayores de 60 años sobre el conjunto de la población fue aumentando. En 1930, los mayores de 60 años representaban $6.6 \%$ del total de la población, consecuencia de una mayor esperanza de vida y del fin de la etapa de inmigración a las minas de hierro.

Por otra parte, también la composición dentro de los diferentes grupos de edad de los mayores de 60 años presentó cambios importantes, como se aprecia en el cuadro 20. Superado el deterioro de las condiciones de vida y trabajo que caracterizaron los primeros años de la explotación intensiva del mineral, con el consiguiente impacto en la mortalidad de los varones adultos (Pérez-Fuentes, 1993), el aumento de la esperanza de vida se reflejó en el aumento de los ancianos de mayor edad. En casi un siglo, el peso de los mayores de 70 años sobre el total de la población mayor de 60 años pasó de $5 \%$ en 1857 en el caso de los hombres a $27.7 \%$ en 1930 ; en el caso de las mujeres los porcentajes aumentaron de $13 \%$ en 1857 a $31 \%$ en 1930.

\footnotetext{
${ }^{8}$ En el Padrón de 1887, que es el primero que incluye a los inmigrantes asentados en chavolas y barracones, $70 \%$ de éstos eran castellanos; $20 \%$ originarios de la provincia de Vizcaya, y 10\% de otras provincias vascas (Pérez-Fuentes, 1993: 37).
} 
CUADRO 20

Estructura de edades de los mayores de 60 años en San Salvador del Valle (Vizcaya)

\begin{tabular}{lrrrrrrrrr}
\hline & \multicolumn{4}{c}{ Hombres } & & \multicolumn{4}{c}{ Mujeres } \\
\cline { 2 - 5 } \cline { 6 - 9 } Edad & 1857 & 1887 & 1900 & 1930 & & 1857 & 1887 & 1900 & 1930 \\
\hline $60-64$ & 70.0 & 55.9 & 51.2 & 40.5 & & 73.9 & 59.0 & 40.6 & 34.6 \\
$65-69$ & 25.0 & 28.8 & 23.8 & 31.8 & & 13.1 & 22.9 & 30.2 & 34.2 \\
$70-74$ & 5.0 & 6.8 & 13.1 & 17.3 & & 8.7 & 6.6 & 21.9 & 12.7 \\
75 y más & 0.0 & 8.5 & 11.9 & 10.4 & & 4.3 & 11.5 & 7.3 & 18.5 \\
Total & 100.0 & 100.0 & 100.0 & 100.0 & & 100.0 & 100.0 & 100.0 & 100.0 \\
\hline
\end{tabular}

Fuente: Elaboración de los autores a partir de los padrones de población de $1857,1887,1900$ y 1930.

Un aspecto a destacar respecto a la población mayor de 60 años son los pronunciados desequilibrios entre los sexos en la zona minera. En este caso la situación es opuesta a la de Bilbao, no sólo como resultado de la inmigración masculina, sino también por la emigración de mujeres a la capital para trabajar en el servicio doméstico. La razón de masculinidad era muy elevada, sobre todo entre los jóvenes y los adultos y, además, era muy variable incluso entre los mayores (véase el cuadro 21), como corresponde a un tipo de inmigración vinculada a un merzado de trabajo tan inestable y dependiente de la demanda exterior de una materia prima que no permitía su almacenamiento.

Muchos de los hombres atraídos por unos ingresos superiores a os que podían ganar como jornaleros agrícolas en tierras castellanas

UADRO 21

lazón de masculinidad de la población mayor de 60 años en San Salvador lel Valle

\begin{tabular}{lrrrr}
\hline dad & 1857 & 1887 & 1900 & 1930 \\
\hline $0-64$ & 82.3 & 63.9 & 110.3 & 130 \\
$5-69$ & 166.7 & 121.4 & 68.9 & 103.4 \\
$0-74$ & 50 & 100 & 52.4 & 151.5 \\
lás de 75 & 100 & 71.5 & 142.8 & 62.5 \\
\hline
\end{tabular}

Fuente: Elaboración de los autores a partir de los padrones de población de $357,1887,1900$ y 1930. 
trabajaron en las minas sólo durante unos meses, otros lo hicieron durante unos años, y sólo una parte de ellos envejeció en la zona minera. Ésta es la causa que atempera la razón de masculinidad de los mayores en relación con otros grupos más jóvenes. ${ }^{9}$ Pero aunque muchos abandonasen las minas, el hecho es que tanto en 1900 como en 1930 la proporción de hombres de 60 a 64 años por cada 100 mujeres de la misma edad era anómalamente alta como consecuencia de las dinámicas de género de un mercado de trabajo radicalmente opuesto al que vimos en Bilbao.

Respecto a la morfología de los hogares donde vivían los mayores de 60 años comenzaremos por indicar que este municipio se inserta en una zona de Vizcaya, Las Encartaciones, de clara implantación de familia nuclear. La proporción de familias complejas era inferior a la del conjunto del agro vizcaíno y, más concretamente, las familias múltiples tenían una de las proporciones más bajas de la Vizcaya rural (Arbaiza, 1996: 322). Es en este contexto de familia nuclear predominante, tanto en lo referido a la población autóctona como a la inmigrante -de nuclearidad más estricta aún-y de acelerados cambios socioeconómicos, en el que vamos a analizar las formas de corresidencia de los mayores.

El cuadro 22 representa la morfología de los hogares en los que vivían los mayores de 60 años, independientemente de que éstos fuesen cabezas de familia o no. En 1857, en un contexto todavía agrario y de minería artesanal, la estructura predominante de los hogares donde habitaban los varones mayores era claramente nuclear. De los ancianos, $\mathbf{7 5 \%}$ corresidían con su cónyuge y/o con algún hijo, o bien eran viudos con hijos solteros en el hogar. Tan sólo $15 \%$ vivía en hogares complejos, cuyaijefatura, en ocasiones, la podían encabezar los hijos propios o políticos. El hecho de que la mayoría de los hombres mayores estuviese en hogares simples ratifica la nuclearidad dominante de las pautas familiares, aunque la solidaridad intergeneracional llevase a establecer modelos intermedios en determinadas circunstancias. De esta manera se entiende que la mayor esperanza de vida de las mujeres y las posibilidades de pasar sus últimos días viudas y sin hijos en el hogar, se tradujese, por el contrario, en un elevado porcentaje de mujeres en hogares complejos: casi 50 por ciento.

${ }^{9}$ En 1887 y 1900 en el grupo de edad de 15 a 29 años había más de 300 hombres por cada 100 mujeres. En 1900 eran más de 450 hombres por cada 100 mujeres entre 20 y 24 años (Pérez-Fuentes, 1993: 112). 
CUADRO 22

Estructuras de los hogares en los que viven los mayores de 60 años en San Salvador del Valle (porcentajes)

\begin{tabular}{|c|c|c|c|c|c|c|c|c|}
\hline & \multicolumn{2}{|c|}{1857} & \multicolumn{2}{|c|}{1887} & \multicolumn{2}{|c|}{1900} & \multicolumn{2}{|c|}{1930} \\
\hline & Hombres & Mujeres & Hombres & Mujeres & Hombres & Mujeres & Hombre & Mujeres \\
\hline Solitarios* & 5.0 & 8.6 & 30.5 & 4.9 & 25.0 & 13.5 & 17.6 & 2.7 \\
\hline Sin estructure & ra 5.0 & .0 & 3.4 & 4.9 & .0 & 2.1 & 1.4 & 3.1 \\
\hline Simples & 75.0 & 43.5 & 49.2 & 50.8 & 54.8 & 44.8 & 49.5 & 49.6 \\
\hline $\begin{array}{l}\text { Extensos y } \\
\text { múltiples }\end{array}$ & 15.0 & 47.8 & 16.9 & 39.3 & 20.2 & 39.6 & 31.5 & 44.6 \\
\hline
\end{tabular}

* Además de los ancianos en hogares solitarios, están los que viven en calidad de huéspedes de otras familias con las que no tienen ninguna relación de parentesco. En este caso las estructuras familiares de dichos hogares no han sido consideradas.

Fuente: Datos elaborados por los autores a partir de los padrones de población de $1857,1887,1900$, y 1930 .

Pocos ancianos vivían solos o sin parientes por estas fechas en la zona minera. Apenas 5\% de los hombres mayores estaba en esta situación. En el caso de las mujeres, las posibilidades de vivir solas o sin familiares eran algo superiores, como suele ser habitual por su mayor esperanza de vida; pero tales posibilidades eran mucho menores de las que tenían las mujeres de este grupo de edad en Bilbao, donde los niveles de soledad eran considerablemente más elevados en 1825 .

No parece que la nuclearidad en el sistema familiar conllevase en esta zona mayor soledad que en las zonas troncales de la Navarra rutal en el siglo XVIII que hemos visto anteriormente, y desde luego, los porcentajes de ancianos en hogares solitarios eran mucho menores que lo que reflejan los datos elaborados por Reher para una zona de estricta nuclearidad como es Cuenca entre 1851 y 1875 . Parecería cono si en el País Vasco, incluso en las zonas de sistema nuclear predoninante, la familia expresase su fortaleza como institución precisanente mediante la capacidad de adaptarse a las situaciones que equieren mayor nivel de complejidad en los hogares.

Ahora bien, sí pudimos apreciar algunos cambios importantes en as formas de residencia de los mayores, sobre todo en las décadas de nayor intensidad en la explotación del mineral y de mayor impacto ociodemográfico. En este periodo las posibilidades de vivir en un hoar nuclear disminuyeron para los hombres, sin que aumentasen paalelamente las posibilidades de formar parte de hogares complejos. 'or el contrario, aumentó de manera notable la proporción de hom- 
bres ancianos que vivian en hogares solitarios o en hogares en los que no tenían ninguna relación de parentesco con el resto de los miembros. En 1887 un tercio de los mayores estaba fuera de un hogar familiar, y estos niveles se mantuvieron, con pocas variaciones, en 1900. En cuanto a las ancianas, el aumento de la soledad en ese fin de siglo también fue relevante, si bien se partía de niveles mucho más bajos que los de Bilbao. Si en 1887 las mujeres mayores que vivían solas apenas alcanzaron $5 \%$, en 1900 la proporción casi se triplicó.

El paso de 5 a $30.5 \%$ de hombres en estas condiciones es un valioso indicador de hasta qué punto se produjo una dislocación de los modos de vida en estas localidades mineras receptoras de fuertes oleadas de inmigrantes. Pero también es cierto que estos niveles de aproximadamente $30 \%$ son semejantes a los que existían en Cuenca en la segunda mitad del siglo. Tal vez en los datos de Reher podríamos estar viendo la otra cara de la moneda de los efectos de las migraciones castellanas hacia los núcleos industriales del norte de España, pero ésta no deja de ser todavía una hipótesis para futuras investigaciones.

La década de los treinta, pasado el boom minero, nos presenta un panorama bastante diferente. Con un mercado de trabajo a la baja, San Salvador del Valle tenía una población de estructura más equilibrada y más estable que en las décadas pasadas. Miles de familias estaban ya asentadas y llevaban años viviendo en el municipio, cuando no habían nacido en él. En este contexto podemos observar que la proporción de hombres mayores que vivían en familias nucleares continuó descendiendo en relación con 1900 compensándose, en este caso, con el aumento de los que vivian en hogares complejos. De hecho en 1930 más de $30 \%$ de los ancianos formaba parte de familias complejas. Los hombres ganaban esperanza de vida, perdiendo con ello posibilidades de encabezar un hogar nuclear, pero al mismo tiempo aumentaban notablemente las oportunidades que tenían de vivir en hogares complejos, siendo cabezas de los mismos o no.

Sin embargo, $17.6 \%$ de los ancianos varones continuó en soledad o sin parientes en el hogar. Ahora bien, este fenómeno de la persistencia de mayores niveles de soledad de los ancianos varones que en Bilbao, y al que nos referiremos más adelante, no puede llevarnos a infravalorar la importancia que tuvo el aumento de los ancianos de ambos sexos que vivían en hogares complejos respecto a 1887 y a 1900. Pese a las difíciles condiciones de vida que siempre han rodeado a la zona minera -en comparación con la capital o los municipios siderúrgicos- lo cierto es que pasadas las fases de inmigraciones más 
intensas y con una población más integrada, la familia nuclear muestra, al igual que en el caso de Bilbao, una notable capacidad de adaptación y de atención a los mayores.

Al examinar el padrón de 1930 también podemos advertir cambios importantes en las modalidades de corresidencia de las mujeres. Al igual que en el caso de Bilbao, la mayor esperanza de vida y la dependencia económica refuerzan la protección familiar hacia las ancianas, como lo demuestra el aumento de éstas en hogares complejos. La disminución de las que vivían solas o sin parientes en el hogar llega a hacer de esta modalidad de corresidencia algo casi excepcional, con 2.7 por ciento.

Pero no sólo descendieron los niveles de soledad respecto a las décadas anteriores, sino que el perfil de estos ancianos solitarios ha variado, como podremos comprobar. Al igual que ocurría en el caso de las mujeres en Bilbao, cuestionamos la naturaleza de este fenómeno. ¿Los niveles de soledad de los hombres mayores en la zona minera entre 1887 y 1930 se explican porque muchos de ellos eran jornaleros inmigrantes y solteros? $O$ por el contrario, ¿eran el resultado de la muerte del cónyuge y del abandono temprano del hogar de los hijos y de las hijas? Son preguntas clave sobre la capacidad de respuesta de este modelo de familia en condiciones que dificultan la expresión de la solidaridad intergeneracional en términos de corresidencia padres-hijos. El estudio se realizó con la totalidad del universo y eso nos permitió contestar a algunas de estas preguntas.

No se trata de abundar en este texto en datos microanalíticos, peo sí nos parece relevante resaltar algunos datos y reflexiones. Tanto ən 1887 como en 1900 la mayor parte de los varones que vivían sin faniliares en el hogar eran viudos: $72 \%$ en 1887 y $91 \%$ en 1900 . En el aso de las mujeres, $75 \%$ de las ancianas que vivían solas también sran viudas y $100 \%$ en 1900 . Este dato abunda en la idea de que cieros factores externos -referidos al mercado de trabajo y a la movilidad le las personas- desestructuraban las pautas familiares o dificultaban a corresidencia de dos generaciones. El resultado es que cuando se roducía la ruptura del núcleo familiar por muerte de uno de los ónyuges, aumentaba la soledad de los viudos y de las viudas.

Sin embargo, en 1930, sólo $34 \%$ de los hombres que vivían en esas circunstancias eran viudos. En este caso la soledad afectaba a los iejos inmigrantes solteros que habían vivido y sobrevivido en este ıunicipio. La mayoría se encontraba en calidad de huéspedes de tras familias. Estos hombres, a juzgar por los años de residencia en 
las minas, formaron parte de los flujos dejóvenes inmigrantes que llegaron tiempo atrás y no constituyeron un hogar propio ni tampoco abandonaron el pueblo cuando la explotación del mineral decayó. La decisión de emigrar, tomada en otro momento de sus vidas, dificultó a muchos hombres la posibilidad de contraer matrimonio. Como se ve en el cuadro 23, existían importantes diferencias en los niveles de soltería de los ancianos entre las últimas décadas del siglo XIX y $1930 .{ }^{10} \mathrm{La}$ relación entre la soltería de los hombres mayores y la soledad es manifiesta y es, en definitiva, el resultado de una determinada estructura de mercado de trabajo y de patrón migratorio que acompañaron al desarrollo de esta región.

CUADRO 23

Estado civil de la población mayor de 60 años en San Salvador del Valle (porcentaje)

\begin{tabular}{lrrrrrrrr}
\hline & \multicolumn{3}{c}{ Hombres } & & \multicolumn{3}{c}{ Mujeres } \\
\cline { 2 - 3 } \cline { 7 - 8 } & Solteros & Casados & Viudos & & Solteras & Casadas Viudas \\
\hline 1857 & 5.0 & 70.0 & 25.0 & & .0 & 26.1 & 73.9 \\
1887 & 3.4 & 56.0 & 40.6 & & 4.9 & 39.4 & 55.7 \\
1900 & .0 & 54.8 & 45.2 & & 1.0 & 39.6 & 59.4 \\
1930 & 12.5 & 58.8 & 28.7 & & 2.3 & 50.8 & 46.9 \\
\hline
\end{tabular}

Fuente: Elaboración de los autores a partir de los padrones de población de $1857,1887,1900$ y 1930.

Los ajemplos de una ciudad como Bilbao y de un municipio minero como San Salvador del Valle, nos indican cómo durante las primeras fases de la industrialización, sobre todo cuando se trata de procesos acelerados e intensos acompañados de fuertes movimientos migratorios, los desajustes sociales y demográficos afectan la capaci-

${ }^{10}$ La temporalidad de los flujos inmigratorios, debido a la inestabilidad del trabajo en las minas, no conduce al asentamiento definitivo de muchos de los trabajadores, y por tanto, los índices de soltería definitiva de los hombres de 46-50 años, aun siendo de los más altos de España, son inferiores a de lo que el desequilibrado mercado matrimonial anunciaba: en 1887 es de 9.8 y en 1900 es de 15.7. A partir de 60 años los índices de soltería todavía disminuyen más, lo que indica que no habiendo formado familia propia, una parte importante de los trabajadores de las minas abandonaba el municipio (Pérez-Fuentes, 1993: 123). 
dad de respuesta del grupo familiar para con los mayores. Estos desajustes, en estrecha relación con la estructura de los mercados de trabajo y con los patrones migratorios, afectaban de manera bien diferenciada a mujeres y a hombres.

Sin embargo, si tenemos en cuenta una visión de más largo plazo, la conclusión es que con el nacimiento de la sociedad industrial en España, y especialmente en el País Vasco, la familia salió reforzada en lo que respecta a las posibilidades de los mayores de corresidir en un hogar familiar. Se refuerza la idea de la capacidad de adaptación de las familias nucleares a los cambios históricos, pese a los desajustes producidos en determinadas coyunturas, y su transformación en hogares extensos en determinadas fases del ciclo vital de los progenitores. La industrialización y los grandes cambios habidos en la región industrial por excelencia de España -pese al aumento de la esperanza de vida- no parecen haber socavado la importancia del hogar familiar como lugar en el que vivían los mayores de 60 años.

\section{Pautas asistenciales a la vejez en España}

Tal y como anunciamos al principio del texto, en este apartado nos referiremos solamente a las pautas asistenciales a la vejez constatadas en las zonas rurales de Cuenca y del norte y centro de Navarra, debido a que hasta el momento tales pautas han sido descritas solamente para esas zonas.

En relación con Cuenca, Reher (1988: 201-216 y 227-230) se fundamentó en el análisis de documentación notarial y en entrevistas orales. Según indica tal autor, como era esperable en este contexto de familia nuclear, la herencia se repartía por lo general en partes iguales entre los hijos supervivientes. Sólo de forma excepcional se empleaban mecanismos de mejora para recompensar los servicios especiales que hubiera prestado algún hijo en periodos de enfermedad o de ancianidad. No obstante, los hijos no tenían que esperar hasta el fallecimiento de los padres para disfrutar de forma autónoma porciones patrimoniales de su herencia y así poder establecerse con sus parejas. Los hijos podían acceder al usufructo de los bienes de los que luego serían propietarios antes de la muerte de los padres gracias a las cesiones que éstos efectuaban en su favor en el momento de su matrimonio. Al llegar a la vejez, cuando la madre enviudara o el patre no pudiera continuar con las labores del campo, era habitual que 
los padres procediesen al reparto de la mayor parte o de la totalidad de su patrimonio. A cambio, los hijos acordaban de manera informal y puramente verbal abonar a sus padres unas rentas que les permitieran mantenerse. De cualquier forma, no se advierten situaciones de penuria económica en la gente de edad. Aunque los ancianos trataban de seguir viviendo solos el mayor tiempo posible, cuando habiendo enviudado llegaban a una situación en la que no podían valerse por sí solos, residían o bien en su casa en compañía permanente de algún hijo, o bien pasaban a convivir por temporadas (por semanas o por meses) con sus diferentes hijos. Los únicos ancianos verdaderamente indigentes eran los que carecían de hijos o de familiares directos. Por lo tanto, de todo ello se puede inferir que esas pautas asistenciales y de solidaridad con los ancianos provocaban que la vejez en el modelo de familia nuclear no tuviera los caracteres dramáticos que habitualmente se han postulado.

Las pautas asistenciales a la vejez vigentes en las zonas septentrionales y centrales de Navarra han sido examinadas por Mikelarena (1995) a partir del análisis de la documentación notarial referida a transmisiones patrimoniales del periodo $1750-1789$ de tres valles concretos. Tales pautas aparecen en su mayor parte especificadas y reguladas en varias cláusulas de los contratos matrimoniales, documentos sobre los que descansaban los mecanismos de sucesión de bienes y de articulación de la familia.

La primera cláusula es la de la mención de la corresidencia entre donadores y donatarios. Esa cláusula suele ser la primera condición que sigue a la donación de los bienes y se expresa habitualmente así: "que los donadores y donatarios hayan de vivir en una casa, mesa y compañía". En la mayor parte de la Navarra troncal los donadores seguían al frente de la administración de la casa hasta donde lo permitiera el mantenimiento de sus capacidades rectoras. Solamente en algunos valles septentrionales los donadores no acostumbraban a reservarse la administración de la casa y el usufructo. En ellos la cesión era inmediata, reformulándose la cláusula antes mencionada en la siguiente forma: "que los donadores y donatarios hayan de vivir en una casa, mesa y compañía, corriendo los últimos, desde el día que contraigan matrimonio, que es cuando principiará a surtir sus efectos este contrato, con la dirección, gobierno y mando, sin perjuicio de conservar a los primeros todo el respeto debido". Otra fórmula utilizada es la siguiente: "que será obligación de los mismos donatarios el alimentar, vestir y calzar a sus padres donadores sanos y enfermos, 
asistiéndoles con todo lo necesario, y el hacerles a su fallecimiento el entierro de su clase y honras de cuatro días, sin exigir que en vida trabajen más que lo que buenamente puedan y permitan sus fuerzas".

La segunda cláusula a la que nos referiremos hace referencia a la reserva en beneficio de los donadores de algunas pequeñas cantidades en metálico o al goce de algunos bienes inmuebles o pecuarios con la finalidad de destinar dineros a sus gastos particulares. Por lo general, en la inmensa mayoría de los casos se trataba de pequeñas cantidades dinerarias, inferiores a los 50 ducados. En las zonas donde la cesión del usufructo de los bienes era inmediata en favor de los donatarios, los donadores se reservaban cantidades dinerarias y también bienes inmuebles y pecuarios e incluso llegaban a imponer al donatario la obligación de abonar una cantidad fija de dinero al mes o al año o de proporcionar alimentos especificados con detalle.

Con todo, el mecanismo de autodefensa de los padres donadores frente al hijo y la nuera o la hija y el yerno donatarios era la cláusula en previsión de que la corresidencia entre ambas partes llegara a deteriorarse. En esa cláusula se especificaba qué bienes irían a cada pare en caso de llegarse a la separación entre unos y otros. Esta cláusula, ¿n la medida en que conllevaba que los donadores asumieran para sí en salidad de usufructuarios hasta su muerte una parte importante de os bienes (por lo general, dos tercios de ellos) hacía que los dueños óvenes de la casa se preocuparan por ser cuidados en el trato y en la :onsideración con aquellos ya que, de lo contrario, se enfrentaban :on el riesgo de hacerse cargo durante unos años de una explotación graria bastante menos viable económicamente. Que las condiciones le separación expresadas en esa cláusula de los contratos no eran mea retórica y que podía llegarse a ellas en la práctica lo demuestran los rotocolos de separación de bienes, algunos de ellos reproducidos en tikelarena (1995: 346-349), para quien las rupturas solían ser poco abituales entre los propietarios con una situación material medianaiente saneada, siendo las discordias mucho más frecuentes cuando ss recursos patrimoniales eran menores y además se encontraban ravemente amenazados por el endeudamiento.

Dicho todo ello, ¿cómo era la posición de los ancianos en contexss rurales de familia troncal como los de la Navarra septentrional y sntral?, ¿era mejor o peor que en contextos rurales de familia nuclear? reemos que esa pregunta es de dificil respuesta, al menos con los dais por ahora disponibles. Sería preciso realizar estudios microanalítiis basados en la consulta de documentación notarial y procesal y en la 
realización de encuestas orales tanto en unos contextos como en otros y, con todo, aún después de hacerlos seguiríamos teniendo problemas para contestar aquel interrogante. Probablemente, en el caso de que las pautas asistenciales descritas para Cuenca y el norte y centro de Navarra fueran representativas, lo más correcto sería pensar que no había diferencias sustanciales en la posición de los viejos, sobre todo de los más ancianos, en un modelo familiar y en otro, y que factores como los sentimientos y la personalidad de los individuos serían más cruciales de lo que inicialmente podría pensarse. De cualquier forma, en contra de la opinión de que la familia troncal era un contexto favorable para la ancianidad podemos citar un sermón en lengua vasca de principios del siglo XIX en el que se hacía el siguiente comentario: "¿No están muchos padres ancianos de sobra en su propia casa, no atreviéndose a decir palabra, arrinconados, reducidos a silencio, temblando en su casa, mandándoles con mal ceño y palabra dura el hijo o la hija, o el yerno o la nuera o todos?" (Caro Baroja, 1976: 127).

\section{Bibliografía}

Arbaiza, M. (1996), Familia, trabajo y reproducción social. Una perspectiva microhistórica de la sociedad vizcaína a finales del Antiguo Régimen, Bilbao.

Caro Baroja, J. (1976), "Sobre la familia vasca", en Baile, familia y trabajo, San Sebastián, pp. 123-132.

Contreras, J. (1991), "Los grupos domésticos: estrategias de producción y reproducción", en Antropología de los pueblos de España, Madrid, pp. 343-380.

Fauve-Chamoux, A. (1985), "Vieillesse et famille-souche", Annales de Demographie Historique, pp. 111-125.

Gómez, G. (1896), Cómo se vive y se muere en Bilbao. Reseña demográfica de la Ilustre Villa, Bilbao.

Hajnal, J. (1965), "European Marriage Patterns in Perspective", en D. V. Glass y D. E. Eversley (eds.), Population in Histony: Essays in Historical Demography, Londres.

Laslett, P. (1972), "Introduction: The History of the Family", en P. Laslett y R. Wall (comps.), Household and Family in Past Time, Cambridge.

Lisón Tolosana, C. (1975), "Estructura antropológica de la familia en España", en La familia, diálogo recuperable, Madrid.

Mikelarena, F. (1992), "Las estructuras familiares en la España tradicional: geografía y análisis a partir del censo de 1860", en Boletín de la Asociación de Demografia Histórica, vol. X, núm. 3, pp. 15-61.

(1994), "Estructuras familiares, ciclo de vida, composición del hogar y mano de obra extrafamiliar en el seno de los grupos domésticos de una 
ciudad tradicional: el ejemplo de Pamplona en 1786", Boletin de la ADEH; vol. 12, núm. 2-3, pp. 125-147.

(1995), Demografía y familia en la Navarra tradicional, Pamplona.

— y Erdozäin, P. (1998), "El hogar en Pamplona en 1786", Principe de Viana.

Pareja, A. y M. Arbaiza (1995), "Naturaleza y evolución del sistema demográfico en Bilbao", en M. Gónzalez Portilla (dir.), Bilbao en la formación del País Vasco Contemporáneo, Bilbao.

Pérez-Fuentes, P. (1993), Vivir.y morir en las minas. Estrategias familiares y relaciones de género en la primera industrialización vasca: 1877-191'3, Bilbao.

y M. Arbaiza, (1995), "Familia, matrimonio y reproducción social", en M. Gónzalez Portilla (dir.), Bilbao en la formación del País Vasco Contemporáneo, Bilbao.

— y A. Pareja (1997), Ageing:Alone or in a Family: The Case of Bilbao, 18251935.

Reher, D. S. (1988), Familia, población y sociedad en la provincia de Cuenca, 17001970, Madrid.

Wall, R. (1991), "Les relations entre générations en Europe autrefois", Annales de Dèmographie'Historique, pp. 135-154. 